\title{
Effect of Autoclaving Cycles on the Cyclic Fatigue Resistance of Race and Race Evo Nickel-Titanium Endodontic Rotary Files: An In Vitro Study
}

\author{
Rahaf A. Almohareb $\left.{ }^{1}{ }^{(}\right)$, Reem Barakat ${ }^{1, *}$, Aroob Albakri ${ }^{2}$ and Manal Altamimi ${ }^{2}$ \\ 1 Clinical Dental Sciences Department, College of Dentistry, Princess Nourah Bint Abdulrahman University, \\ Riyadh 11671, Saudi Arabia; raalmohareb@pnu.edu.sa \\ 2 College of Dentistry, Princess Nourah Bint Abdulrahman University, Riyadh 11671, Saudi Arabia; \\ Aroob.ahmed.b@hotmail.com (A.A.); manalaltamimi@outlook.com (M.A.) \\ * Correspondence: rmbarakat@pnu.edu.sa; Tel.: +966-504440598
}

check for updates

Citation: Almohareb, R.A.; Barakat, R.; Albakri, A.; Altamimi, M. Effect of Autoclaving Cycles on the Cyclic Fatigue Resistance of Race and Race Evo Nickel-Titanium Endodontic Rotary Files: An In Vitro Study. Metals 2021, 11, 1947. https:/ / doi.org/10.3390/met11121947

Academic Editor:

Francesco Iacoviello

Received: 9 November 2021

Accepted: 30 November 2021

Published: 2 December 2021

Publisher's Note: MDPI stays neutral with regard to jurisdictional claims in published maps and institutional affiliations.

Copyright: (c) 2021 by the authors. Licensee MDPI, Basel, Switzerland. This article is an open access article distributed under the terms and conditions of the Creative Commons Attribution (CC BY) license (https:// creativecommons.org/licenses/by/ $4.0 /)$

\begin{abstract}
Objective: The aim of this study was to evaluate the influence of autoclave sterilization on the resistance to cyclic fatigue of two nickel-titanium (NiTi) endodontic files of identical design and taper, but with different NiTi alloy treatments: the newly introduced heat-treated Race Evo and the electropolished Race files. Materials and methods: Fifteen Race (25/0.06) files and fifteen Race Evo (25/0.06) files ( $\mathrm{n}=30$ in total) were randomly assigned to five sub-groups each consisting of three files of the same NiTi alloy treatment. One group served as a control with files unautoclaved. The four remaining groups were sterilized in a steam sterilizer for 1, 3, 5, and 10 autoclave cycles, respectively. Files then underwent cyclic fatigue testing in a simulated metal canal block. A scanning electron microscope was used to inspect the surface of the fractured instruments. Statistical analysis was conducted using independent $t$-test and multi-factorial analysis of variance with significance set at a $p$ value of $\leq 0.05$. Results: Both Race Evo and Race files showed no significant difference between the different autoclaving cycles in terms of the number of cycles to fracture $(p=0.232$ and $p=0.359$ ). Despite rotating at a higher speed, the number of cycles to fracture of heat-treated Race Evo files was significantly higher than that of Race files $(p \leq 0.0001)$. Conclusion: Autoclave sterilization has no significant effect on the resistance to cyclic fatigue of heat-treated Race Evo or electropolished Race files. However, Race Evo files showed superior resistance to cyclic fatigue irrespective of autoclaving cycles.
\end{abstract}

Keywords: autoclave; cyclic fatigue; heat treatment; NiTi; race; scanning electron microscope

\section{Introduction}

Nickel-titanium (NiTi) rotary files can provide faster and more predictable instrumentation of root canal systems. This alloy, which contains nearly 56\% (wt) nickel and $44 \%$ (wt) titanium, grants them key properties, such as shape memory and super elasticity, which have allowed them to revolutionize root canal instrumentation [1,2]. However, these NiTi instruments have been plagued with a high risk of fracture related to either torsional or flexural fatigue. A NiTi file rotating in a curved canal is subjected to a set of continuous compressive and tensile stresses that results in its flexural (cyclic) fatigue [3]. Many factors influence cyclic fatigue: canal curvature, instrument dimensions, design, and manufacturing process. Advancements in the manufacturing of the NiTi alloy itself, such as thermal treatment [4] and surface treatment, have been suggested to enhance fatigue resistance [5-7].

The NiTi alloy exists in three crystallographic phases: austenite, martensite, and Rphase. The martensite microstructure shows superior resistance to cyclic fatigue. Heattreatment alters the temperature at which the microstructure of the NiTi alloy shifts from one phase to another, adopting in the process the specific properties of that phase. As a 
result of subjecting NiTi to specific heat processes, the temperature at which it completes the transformation from the martensite to the austenite phase rises above body temperature, resulting in heat-treated files being used clinically while in the martensite phase, as opposed to conventional NiTi, which is used in the austenite phase [2].

In clinical practice it is necessary, for various reasons, for NiTi files to undergo autoclave sterilization to avoid cross-contamination [8]. Apart from cost, many dental practitioners choose pre-arranged sets of files in which not all files in the set are used during a treatment session.

Because thermal treatment has a significant influence on the mechanical properties of $\mathrm{NiTi}$, the additional heat that files are subjected to during autoclaving procedures may have an effect on the mechanical qualities of these instruments. A recent systematic review [9] reported that the cyclic fatigue resistance of heat-treated NiTi instruments seems to be influenced by autoclave sterilization methods. According to Zhao et al. [6], although thermal-treated HyFlex CM, Twisted File, and K3XF instruments were found to be more resistant to cyclic fatigue failure than Race and K3 instruments, autoclaved HyFlex CM and K3XF instruments were more resistant to cyclic fatigue than Twisted File.

Race (FKG, La-Chaux-de-Fonds, Switzerland) files are constructed of an electropolished NiTi alloy. Its cross-section is triangular, with distinct positive cutting angles [10]. Recently, the Race Evo (FKG Dentaire SA, La Chaux-de-Fonds, Switzerland) file was introduced. The cross-sectional shape was the same as the Race file, with similar alternating cutting blades that minimize screw effect and improve the control of the instrument's movement through the canal [11]. This file is heat-treated in order to optimize the shape memory of the NiTi alloy thereby increasing its flexibility and reducing its susceptibility to cyclic fatigue and fracture. Very little is known regarding the composition and manufacturing of these files. However, their blue color suggests the presence of a titanium oxide layer that enhances their resistance [2].

The effect of autoclave sterilization on newly developed instruments constructed of heat-treated alloys, such as the Race Evo, has not been documented in the literature. Thus, the aim of this in vitro study was to investigate the effect of repeated autoclave cycles on the cyclic fatigue resistance of two files of identical design and cross section, but different NiTi alloy composition and treatment: the Race $(25 / 0.06)$ and Race Evo (25/0.06) files. The null hypothesis was that no difference in the impact of multiple autoclave cycles on cyclic fatigue resistance existed between the Race (25/0.06) and Race Evo (25/0.06) files.

\section{Materials and Methods}

This randomized controlled in vitro study was exempted according to the Institutional Review Board of Princess Nourah Bint Abdulrahman University in Riyadh, Saudi Arabia (IRB no. 21-0382).

Fifteen Race (25/0.06) files and fifteen Race Evo (25/0.06) files ( $n=30$ in total), all of the same length $(21 \mathrm{~mm})$, were randomly assigned to one of five sub-groups aligned with each type of file. Each sub-group consisted of three files. The first group was classified as the control group and was not autoclave sterilized. The four remaining groups were sterilized using a variable number of autoclave cycles $(1,3,5$, and 10$)$ in a sterilizer using steam (Steris Amsco century prevac steam sterilizer, v-148h, Mentor OH, United States). In each autoclave cycle, the files were treated at a temperature of $132{ }^{\circ} \mathrm{C}$ with a pressure of 29 psi for a period of 4 min which was then followed by a 5 min drying time.

A special metal block was constructed in accordance with Plotino et al. [12], an approved technique for cyclic fatigue testing. This block contained a machined stainlesssteel artificial canal showing a 60 degree angle of curvature, a $5 \mathrm{~mm}$ radius of curvature, a $1.40 \mathrm{~mm}$ inner diameter, and a length of $19 \mathrm{~mm}$ (Figure 1). 


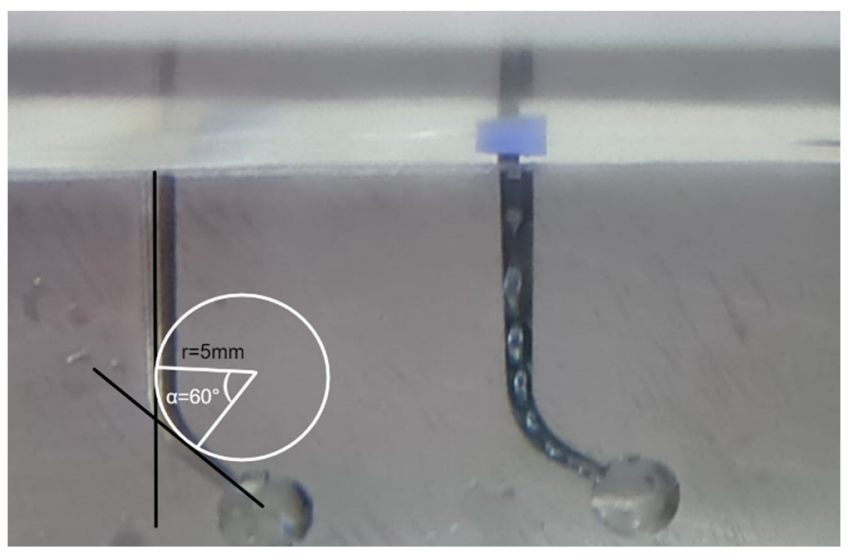

Figure 1. Metal block showing the radius and curvature of the artificial canal.

Both Race and Race Evo files have the same cross-sectional triangular configuration, with distinct positive cutting angles, an active non-cutting tip with a diameter of $0.25 \mathrm{~mm}$ and a continuous taper of $0.06 \mathrm{~mm}$ extending $16 \mathrm{~mm}$ from the tip. Files were inserted into the metal canal then rotated using a 16:1 reduction dental handpiece of an endodontic electric motor (X-Smart; Dentsply Sirona, Ballaigues, Switzerland). The handpiece had been mounted onto a prefabricated jig that allowed the file to be inserted into the artificial canal in a reproducible and accurate manner, while the metal block was immersed in a $35{ }^{\circ} \mathrm{C}$ water bath (Figure 2).

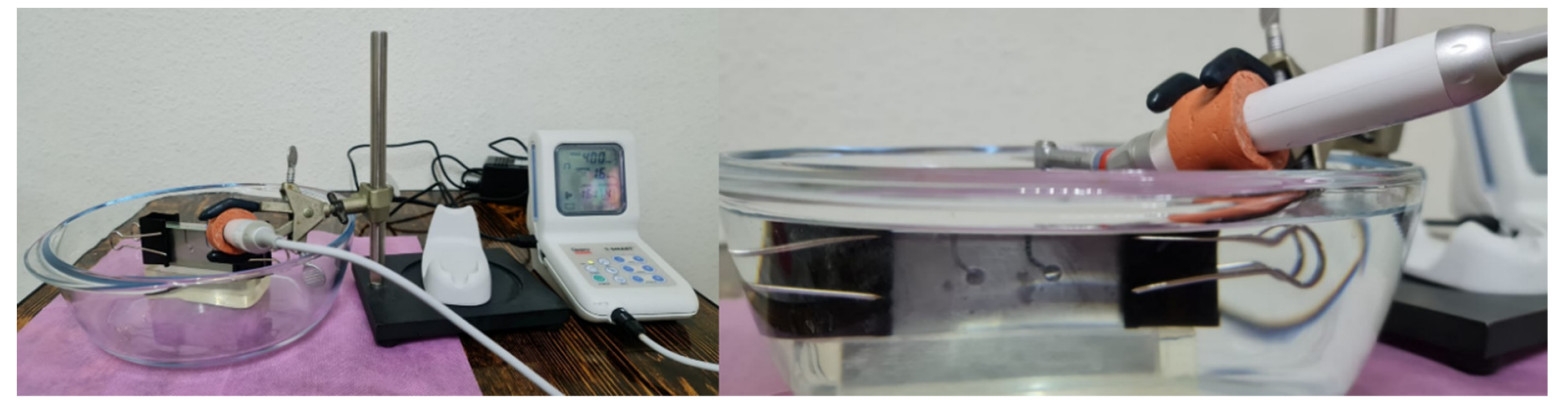

Figure 2. Cyclic fatigue testing device.

All files were rotated in a continuous clockwise motion at constant torques and speeds recommended by the manufacturer until fracture occurred. For Race files, the rotation speed was $400 \mathrm{rpm}$ at a torque of $1.5 \mathrm{Ncm}$, and for Race Evo, $800 \mathrm{rpm}$ at a torque of $1 \mathrm{Ncm}$. Separation was observed both audibly and visually. A digital stopwatch was used to determine the time needed for fracture in seconds to the nearest 1/100 s. Accordingly, the number of cycles to fracture was calculated.

A scanning electron microscope (SEM; JSM-7001F, JEOL, Tokyo, Japan) was used to inspect the fractured instruments and evaluate the topographical characteristics of the fractured surfaces. Photomicrographs of the fractured surfaces were taken at $250 \times$ and $2000 \times$ magnification, in addition to photomicrographs of the lateral surface at $100 \times$ magnification.

Using SPSS (IBM Corp. Released 2013. IBM SPSS Statistics for Windows, Version 22.0. Armonk, NY: IBM Corp.), the normality of the data was checked with the ShapiroWilks test. Accordingly, statistical analysis was conducted using an independent $t$-test and multi-factorial analysis of variance. Statistical significance was set at a $p$ value of $\leq 0.05$.

\section{Results}

For both NiTi file types, the mean time and number of rotations to fracture are shown in Table 1. The number of rotations to fracture for the Race files ranged between 385 rotations 
(recorded after one autoclaving cycle) and 639 after three autoclaving cycles. While Race Evo files failed following a mean number of rotations ranging between 1239 rotations (recorded after ten autoclaving cycles) and 1729 rotations (at five autoclaving cycles) (Figure 3).

Despite rotating at higher speeds, Race Evo files took a significantly longer time and had a higher number of rotations to fracture compared to Race $(p \leq 0.0001)$. However, when comparing different autoclaving cycles, no significant difference was found between the groups, whether the files were Race $(p=0.359)$ or Race Evo $(p=0.232)$ (Table 2$)$.

Table 1. Cyclic fatigue for Race and Race Evo files after different autoclave sterilization cycles.

\begin{tabular}{|c|c|c|c|c|}
\hline NiTi File & $\begin{array}{c}\text { Number of } \\
\text { Autoclave Cycles }\end{array}$ & $\mathbf{N}$ & $\mathrm{NRF} \pm \mathrm{SD}$ & $\begin{array}{l}\text { Time to Fracture } \\
\text { (Seconds } \pm \text { SD) }\end{array}$ \\
\hline \multirow{5}{*}{ Race } & 0 & 3 & $435 \pm 144^{a}$ & $65.27 \pm 21.63$ \\
\hline & 1 & 3 & $385 \pm 76^{a}$ & $57.87 \pm 11.5$ \\
\hline & 3 & 3 & $639 \pm 184^{a}$ & $95.93 \pm 27.63$ \\
\hline & 5 & 3 & $451 \pm 102^{a}$ & $67.77 \pm 15.32$ \\
\hline & 10 & 3 & $522 \pm 217^{a}$ & $78.30 \pm 32.57$ \\
\hline \multirow{5}{*}{ Race Evo } & 0 & 3 & $1585 \pm 256^{b}$ & $118.93 \pm 19.25$ \\
\hline & 1 & 3 & $1466 \pm 98^{b}$ & $110 \pm 7.37$ \\
\hline & 3 & 3 & $1572 \pm 287^{b}$ & $117.93 \pm 21.6$ \\
\hline & 5 & 3 & $1729 \pm 339^{b}$ & $129.73 \pm 25.46$ \\
\hline & 10 & 3 & $1239 \pm 155^{b}$ & $92.933 \pm 11.65$ \\
\hline
\end{tabular}

NRF, number of rotations to fracture; SD, standard deviation. Different lower-case letters in the same column represent statistically significant differences between the groups according to independent $t$-test $(p \leq 0.0001)$.

Table 2. ANOVA analysis comparing number of rotations to failure after various autoclave sterilization cycles.

\begin{tabular}{ccccc}
\hline File Type & N & Mean Square & F & Sig. (2-Tailed) \\
\hline Race & 15 & $29,007.807$ & 1.227 & 0.359 \\
Race Evo & 15 & $99,614.341$ & 1.672 & 0.232 \\
\hline
\end{tabular}

$p$ value was set at $\leq 0.05$.

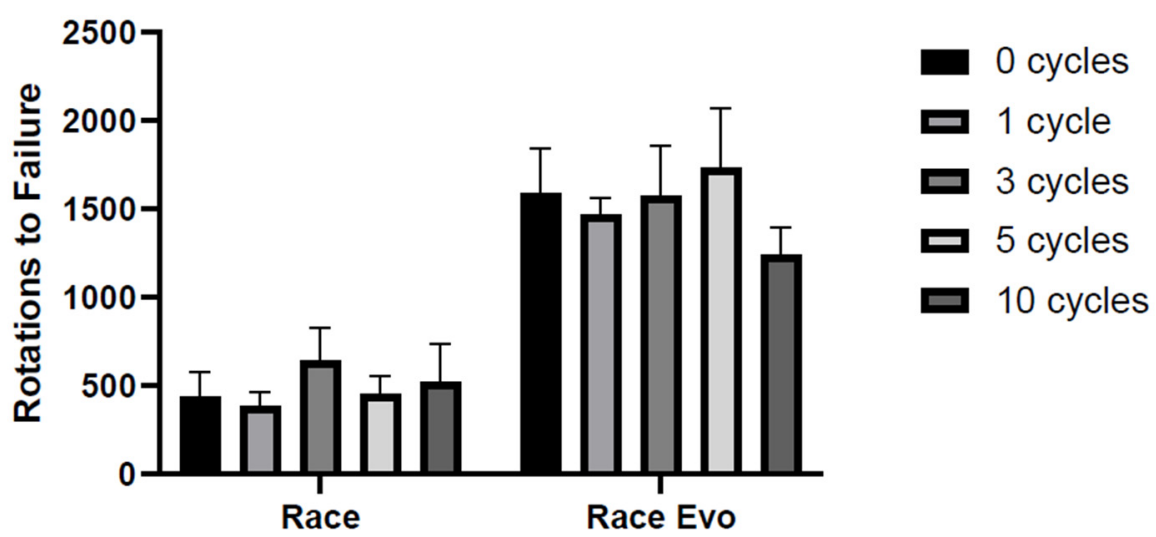

Figure 3. Two-way ANOVA: Mean number of rotations to failure of Race and Race Evo files after different autoclaving cycles.

The SEM photomicrographs can be seen in Figure 4. The images show fractured surfaces pre-autoclaving and then after 5 and 10 cycles. Arrows point to the distinct features on these fracture surfaces. 

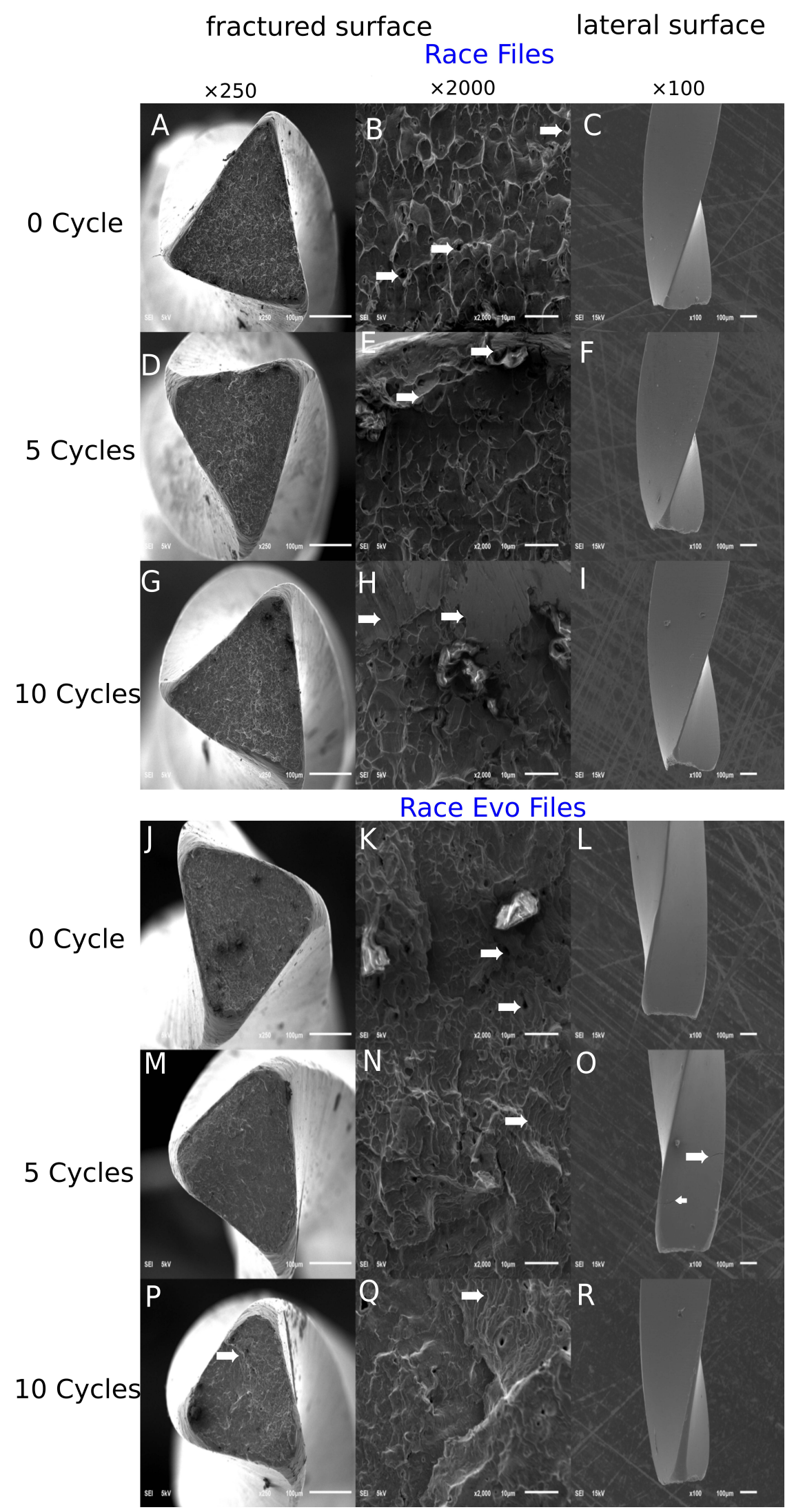

Figure 4. Scanning electron microscope (SEM) images of the fractured surfaces (A-I): Race files, (J-R): Race Evo files) under low magnification $(\times 250)$ and high magnification $(\times 2000)$ pre-autoclaving, then after 5 and 10 autoclaving cycles. White arrows in (B) Dimple features characteristic of ductile failure; (E) Microvoids; (H,O) Crack initiation; $(\mathbf{K}, \mathbf{N}, \mathbf{Q})$ Striation lines (fatigue failure). 


\section{Discussion}

Fracture due to cyclic fatigue remains a frequent cause of NiTi failure during root canal preparation. Previous studies have reported an inverse relationship between the amount of metal mass in the file cross-section and cyclic fatigue [13,14], and it has been suggested that thermal and surface treatment during the manufacturing of the NiTi alloy enhance fatigue resistance [4-7].

Due to economic considerations, these files are subject to multiple uses, which exposes them to autoclave sterilization during their working life. Therefore, the purpose of this study was to evaluate the influence of autoclave sterilization on the resistance to cyclic fatigue of two files of identical design and taper but of different NiTi alloy treatment.

The heat-treated Race Evo file outperformed the conventional electropolished Race file in terms of cyclic fatigue resistance irrespective of the number of autoclaving cycles. This is in accordance with most studies that have shown that the thermomechanical manipulation of the NiTi alloy microstructure enhances its performance, especially in terms of cyclic fatigue resistance [15-17]. By immersing the metal canal block in water heated to $35^{\circ} \mathrm{C}$, the present study was able to simulate the phase transition of the Race Evo files between martensite and austenite at the recommended temperature of $32-35^{\circ} \mathrm{C}$ [18], which would explain the favorable results.

Despite rotating at a high speed of $800 \mathrm{rpm}$, the Race Evo file showed superior cyclic fatigue resistance not only in terms of the number of cycles to failure, but also in terms of time until failure (the mean time to fracture was $1 \mathrm{~min}$ and $13 \mathrm{~s}$ for Race files as compared to $1 \mathrm{~min}$ and $54 \mathrm{~s}$ for Race Evo). The effect of rotational speed on cyclic fatigue is a controversial issue, especially where conventional NiTi files are concerned. Apart from Lopes et al. [19], who reported a $30 \%$ reduction in the number of cycles to fracture of ProTaper instruments when the rotational speed was increased from 300 to $600 \mathrm{rpm}$, other studies $[20,21]$ found that rotational speed has no significant influence on cyclic fatigue, and a higher speed simply reduces the time to failure.

The current study found that autoclave sterilization did not affect cyclic fatigue resistance in either Race Evo or Race files. It appears that the temperatures the files are exposed to during autoclave sterilization may not be high enough to incur serious alterations in the microstructure of the NiTi alloy, which would negatively affect its resistance to fatigue. This finding was echoed in previous studies $[6,8,22,23]$ that detected no detrimental influence of autoclave sterilization on the cyclic fatigue resistance of conventional or heat-treated NiTi files. In fact, Viana et al. [22] reported an increase in the cyclic fatigue resistance of Profile files after 5 autoclaving cycles, while Champa et al. [23] found the same increase in Reciproc files. However, Hilfer et al. [24] reported a decrease in the cyclic fatigue resistance of a size 25/0.06 Twisted File. In their study, not only was the file of a large taper, but the simulated metal canal had a severe curve of $90^{\circ}$.

In order to standardize experimental parameters, files were tested in a canal grooved within a metal block without any back-and-forth movement. Although this static model does not reproduce clinical situations, nor does it replicate the extended distribution of stresses associated with rhythmic movement, it remains the preferred model for evaluating cyclic fatigue used in previous studies $[8,9,13,14]$. That said, the results obtained in this study may not be identically reproducible in clinical settings.

The quality of the file's surface was shown to be critical, as cracks and corrosion may result in instrument fracture $[25,26]$. Praisarnti et al. [27] showed that electropolishing enhanced the resistance to fatigue failure, especially in the presence of corrosive sodium hypochlorite. However, it does not affect the core mechanical properties of the metal itself as heat-treatment does.

Through SEM, fractured surfaces tend to exhibit various textures that reflect the different loads and failure types. Failure as a result of flexural fatigue is usually characterized by linear striations perpendicular to the direction of the tensile stress and areas of crack initiation, while torsional fracture is associated with plastic deformation and dimpling patterns [28]. Race Evo files showed distinct striations typical of flexural fatigue radi- 
ating from an initiation point followed by dimpling, which is characteristic of ductile failure [29]. Features consistent with ductile and microvoid coalescence failure were seen on the fractured surfaces of both types of files [30].

\section{Conclusions}

Autoclave sterilization has no significant effect on the resistance to cyclic fatigue of heat-treated Race Evo or electropolished Race files. However, heat-treated Race Evo files showed superior resistance to cyclic fatigue irrespective of autoclaving cycles.

Author Contributions: R.A.A. and R.B.: designed the study protocol and wrote the manuscript. A.A. and M.A.: material preparation, data collection, and literature review; R.B.: statistical analysis. All authors commented on previous versions of the manuscript. All authors have read and agreed to the published version of the manuscript.

Funding: No funding was received for conducting this study.

Institutional Review Board Statement: This randomized controlled in vitro study was exempted according to the Institutional Review Board of Princess Nourah Bint Abdulrahman University in Riyadh, Saudi Arabia (IRB no. 21-0382).

Data Availability Statement: All data is available upon request through contacting the corresponding author at rmbarakat@pnu.edu.sa.

Conflicts of Interest: The authors declare that they have no conflict of interest.

\section{References}

1. Lopes, N.I.D.A.; Silva, L.; Ávila, D.O.; Santos, L.D.A.; Buono, V.T.L. Surface Characterization of NiTi Superelastic and Shape Memory Alloys After Electrolytic Polishing. Mater. Res. 2017, 20, 572-579. [CrossRef]

2. Shen, Y.; Zhou, H.-M.; Zheng, Y.; Peng, B.; Haapasalo, M. Current Challenges and Concepts of the Thermomechanical Treatment of Nickel-Titanium Instruments. J. Endod. 2013, 39, 163-172. [CrossRef] [PubMed]

3. Shen, Y.; Cheung, G.S. Methods and models to study nickel-titanium instruments. Endod. Top. 2013, 29, 18-41. [CrossRef]

4. Zinelis, S.; Eliades, G.; Eliades, T. A metallurgical characterization of ten endodontic Ni-Ti instruments: Assessing the clinical relevance of shape memory and superelastic properties of Ni-Ti endodontic instruments. Int. Endod. J. 2010, 43, 125-134. [CrossRef] [PubMed]

5. Pedullà, E.; Benites, A.; La Rosa, G.M.; Plotino, G.; Grande, N.M.; Rapisarda, E.; Generali, L. Cyclic Fatigue Resistance of Heat-treated Nickel-titanium Instruments after Immersion in Sodium Hypochlorite and/or Sterilization. J. Endod. 2018, 44, 648-653. [CrossRef] [PubMed]

6. Zhao, D.; Shen, Y.; Peng, B.; Haapasalo, M. Effect of autoclave sterilization on the cyclic fatigue resistance of thermally treated Nickel-Titanium instruments. Int. Endod. J. 2016, 49, 990-995. [CrossRef] [PubMed]

7. Yahata, Y.; Yoneyama, T.; Hayashi, Y.; Ebihara, A.; Doi, H.; Hanawa, T.; Suda, H. Effect of heat treatment on transformation temperatures and bending properties of nickel-titanium endodontic instruments. Int. Endod. J. 2009, 42, 621-626. [CrossRef] [PubMed]

8. Bulem, U.K.; Kececi, A.D.; Guldas, H.E. Experimental evaluation of cyclic fatigue resistance of four different nickel-titanium instruments after immersion in sodium hypochlorite and/or sterilization. J. Appl. Oral Sci. 2013, 21, 505-510. [CrossRef] [PubMed]

9. Silva, E.J.N.L.; Zanon, M.; Hecksher, F.; Belladonna, F.G.; De Vasconcelos, R.A.; Fidalgo, T.K.D.S. Influence of autoclave sterilization procedures on the cyclic fatigue resistance of heat-treated nickel-titanium instruments: A systematic review. Restor. Dent. Endod. 2020, 45, e25. [CrossRef] [PubMed]

10. Keskin, N.B.; Inan, U. Cyclic fatigue resistance of rotary NiTi instruments produced with four different manufacturing methods. Microsc. Res. Tech. 2019, 82, 1642-1648. [CrossRef]

11. Schafer, E.; Vlassis, M. Comparative investigation of two rotary nickel-titanium instruments: ProTaper versus RaCe. Part 2. Cleaning effectiveness and shaping ability in severely curved root canals of extracted teeth. Int. Endod. J. 2004, 37, 239-248. [CrossRef] [PubMed]

12. Plotino, G.; Costanzo, A.; Grande, N.M.; Petrovic, R.; Testarelli, L.; Gambarini, G. Experimental Evaluation on the Influence of Autoclave Sterilization on the Cyclic Fatigue of New Nickel-Titanium Rotary Instruments. J. Endod. 2012, 38, 222-225. [CrossRef] [PubMed]

13. Kaval, M.E.; Capar, I.D.; Ertas, H.; Sen, B.H. Comparative evaluation of cyclic fatigue resistance of four different nickel-titanium rotary files with different cross-sectional designs and alloy properties. Clin. Oral Investig. 2017, 21, 1527-1530. [CrossRef]

14. Plotino, G.; Grande, N.M.; Melo, M.C.; Bahia, M.G.D.A.; Testarelli, L.; Gambarini, G. Cyclic fatigue of NiTi rotary instruments in a simulated apical abrupt curvature. Int. Endod. J. 2010, 43, 226-230. [CrossRef] [PubMed] 
15. Zinelis, S.; Darabara, M.; Takase, T.; Ogane, K.; Papadimitriou, G.D. The effect of thermal treatment on the resistance of nickeltitanium rotary files in cyclic fatigue. Oral Surg. Oral Med. Oral Pathol. Oral Radiol. Endodontol. 2007, 103, 843-847. [CrossRef] [PubMed]

16. Hieawy, A.; Haapasalo, M.; Zhou, H.; Wang, Z.J.; Shen, Y. Phase Transformation Behavior and Resistance to Bending and Cyclic Fatigue of ProTaper Gold and ProTaper Universal Instruments. J. Endod. 2015, 41, 1134-1138. [CrossRef] [PubMed]

17. Braga, L.C.M.; Silva, A.C.F.; Buono, V.T.L.; Bahia, M.G.D.A. Impact of Heat Treatments on the Fatigue Resistance of Different Rotary Nickel-titanium Instruments. J. Endod. 2014, 40, 1494-1497. [CrossRef]

18. Race IFKG Dentaire. Available online: https://www.fkg.ch/products/endodontics/canal-shaping-and-cleaning/race (accessed on 18 June 2021).

19. Lopes, H.P.; Ferreira, A.A.; Elias, C.N.; Moreira, E.J.; de Oliveira, J.C.M.; Siqueira, J.F. Influence of Rotational Speed on the Cyclic Fatigue of Rotary Nickel-Titanium Endodontic Instruments. J. Endod. 2009, 35, 1013-1016. [CrossRef]

20. Daugherty, D.W.; Gound, T.G.; Comer, T.L. Comparison of Fracture Rate, Deformation Rate, and Efficiency Between Rotary Endodontic Instruments Driven at $150 \mathrm{rpm}$ and $350 \mathrm{rpm}$. J. Endod. 2001, 27, 93-95. [CrossRef] [PubMed]

21. Zelada, G.; Varela, P.; Martín, B.; Bahíllo, J.G.; Magán, F.; Ahn, S. The Effect of Rotational Speed and the Curvature of Root Canals on the Breakage of Rotary Endodontic Instruments. J. Endod. 2002, 28, 540-542. [CrossRef]

22. Viana, A.C.D.; Gonzalez, B.M.; Buono, V.T.L.; Bahia, M.G.A. Influence of sterilization on mechanical properties and fatigue resistance of nickel-titanium rotary endodontic instruments. Int. Endod. J. 2006, 39, 709-715. [CrossRef] [PubMed]

23. Divya, V.; Sadashiva, P.; Champa, C.; Srirekha, A.; Karale, R.; Shetty, A. An analysis of cyclic fatigue resistance of reciprocating instruments in different canal curvatures after immersion in sodium hypochlorite and autoclaving: An in vitro study. J. Conserv. Dent. 2017, 20, 194-198. [CrossRef] [PubMed]

24. Hilfer, P.B.; Bergeron, B.E.; Mayerchak, M.J.; Roberts, H.W.; Jeansonne, B.G. Multiple Autoclave Cycle Effects on Cyclic Fatigue of Nickel-Titanium Rotary Files Produced by New Manufacturing Methods. J. Endod. 2011, 37, 72-74. [CrossRef] [PubMed]

25. Ray, J.J.; Kirkpatrick, T.C.; Rutledge, R.E. Cyclic Fatigue of EndoSequence and K3 Rotary Files in a Dynamic Model. J. Endod. 2007, 33, 1469-1472. [CrossRef] [PubMed]

26. Inan, U.; Aydin, C.; Uzun, O.; Topuz, O.; Alacam, T. Evaluation of the Surface Characteristics of Used and New ProTaper Instruments: An Atomic Force Microscopy Study. J. Endod. 2007, 33, 1334-1337. [CrossRef] [PubMed]

27. Praisarnti, C.; Chang, J.W.; Cheung, G.S. Electropolishing Enhances the Resistance of Nickel-Titanium Rotary Files to CorrosionFatigue Failure in Hypochlorite. J. Endod. 2010, 36, 1354-1357. [CrossRef] [PubMed]

28. Azimi, S.; Delvari, P.; Hajarian, H.C.; Saghiri, M.A.; Karamifar, K.; Lotfi, M. Cyclic fatigue resistance and fractographic analysis of RaCe and ProTaper rotary NiTi instruments. Iran. Endod. J. 2011, 6, 80-85. [PubMed]

29. James, B.; Foulds, J.; Eiselstein, L. Failure analysis of NiTi wires used in medical applications. J. Fail. Anal. Prev. 2005, 5, 82-87. [CrossRef]

30. Chen, J.H.; Wang, G.Z.; Sun, W. Investigation on the fracture behavior of shape memory alloy NiTi. Met. Mater. Trans. A 2005, 36, 941-955. [CrossRef] 